\title{
Increasing negative charge and nutrient contents of a highly weathered soil using basalt and rice husk to promote cocoa growth under field conditions
}

\begin{abstract}
Technology intervention is a key success to restore properties and productivities of a highly weathered soil (Oxisols). The main challenge is to find materials with the ability to generate soil negative charge, release various nutrients and suppress toxic elements. The objective of this study was to increase negative charge and nutrient content, and suppress $\mathrm{Al}$ and $\mathrm{Mn}$ toxicities of an Oxisol using finely ground basalt and rice husk compost (RHC) to promote cocoa growth under field conditions. Factorial field experiment of $4 \times 4$ used finely ground basalt and rice husk compost and arranged in a randomly complete block design and planted to cocoa as a test crop. Finely ground basalt and rice husk compost were incorporated to the soil at 0 ï $20 \mathrm{~cm}$ depth and rates varied from 0 to $20 \mathrm{t}$ hai 1 each. Soils were periodically sampled for 24 months for analyses of soil negative charge, organic C content, various cations, $\mathrm{pH}$ and toxic elements. Results showed the rice husk compost (RHC) application significantly increased soil organic $\mathrm{C}$ content. The solid state cross polarization magic angle spinning 13carbon nuclear magnetic resonance (CP/MAS 13C NMR) indicates RHC application was able to increase soil organic $\mathrm{C}$ functional groups (O-alkyl, di-O-alkyl and carboxyl C), accompanied by the appearance of aromatic, alkyl and methoxyl $\mathrm{C}$ as new functional groups. The carboxyl $\mathrm{C}$ plays a major role in generating soil negative charge, suggesting RHC is suitable to restore organic $\mathrm{C}$ and negative charge of Oxisols. Basalt, RHC and their combination were able to increase markedly the negative charge of Oxisols as revealed by the decreases in $\mathrm{pH} 0$ and point zero net charge (PZNC) values. The decrease in $\mathrm{pH} 0$ and PZNC values resulted in the increase of net negative charge of an Oxisol from 0.8 (a control soil) to 2.8, 4.1 and 5.0 cmolc $\mathrm{kgī} 1$ for basalt, RHC and their combinations, respectively. In situ soil solution study (a new technique) under field conditions showed basalt and RHC applications either singly or in combination significantly increased the concentrations of $\mathrm{Ca}, \mathrm{Mg}, \mathrm{K}, \mathrm{Na}$ and $\mathrm{Si}$, while concentrations of toxic $\mathrm{Al}$ and $\mathrm{Mn}$ significantly reduced below a toxic level. Overall improvement of Oxisol chemical properties attributed by basalt and RHC applications significantly increased cocoa growth as revealed by the increase in height and stem diameter of cocoa which are two to three times faster than the control within a 24-month period.
\end{abstract}

Keyword: Basalt; Rice husk; Surface charge; Oxisols; Cocoa 